\title{
The Surgical Morbidity And Oncological Outcome Of Total Laparoscopic Radical Trachelectomy Versus Total Laparoscopic Radical Hysterectomy For Early Stage Cervical Cancer: A Retrospective Study With II-Year Follow-Up
}

This article was published in the following Dove Press journal: OncoTargets and Therapy

Qi Lu

Zhiqiang Zhang

Meizhu Xiao

Chongdong Liu

Zhenyu Zhang (D)

Department of Obstetrics and Gynecology, Chao-yang Hospital, Capital Medical University, Beijing, People's Republic of China
Correspondence: Chongdong Liu; Zhenyu Zhang

Department of Obstetrics and Gynecology, Beijing Chao-yang Hospital affiliated to Capital Medical University, 8 Gongtinanlu, Chaoyang District, Beijing 100020, People's Republic of China Tel +86 I0 13801237287

Fax +861085231507

Email123630006@qq.com;

zhenyuzhang2000@I63.com
Objective: The objective of this study was to evaluate the surgical morbidity and oncological outcome of total laparoscopic radical trachelectomy (TLRT) and total laparoscopic radical hysterectomy (TLRH) in patients with early-stage cervical cancer.

Methods: We performed a retrospective study to compare the outcomes of patients with stage IB1 cervical cancer who underwent TLRT to patients treated with TLRH from January 2005 to December 2016.

Results: Forty-six patients underwent TLRT and 73 patients underwent TLRH between January 2005 and December 2016. The median age was 30 (19-40) years for TLRT group compared to 43 (31-65) years for TLRH group. No significant difference was found for the tumor size, histology, and pathology grade between TLRT group and TLRH group. In the TLRT group, the median operative time was 200 mins (range, 150-360 mins) and the median blood loss was $200 \mathrm{~mL}$ (range, $50-400 \mathrm{~mL}$ ). In the TLRH group, the median operative time was 240 mins (range, 180-380) and the median blood loss was $250 \mathrm{~mL}$ (range, $10-1500 \mathrm{~mL}$ ). The median follow-up time was 80 months for TLRT group and 72 months for TLRH group. No patient in TLRT group developed recurrence. However, there were 2 recurrences diagnosed in the TLRH group.

Conclusion: TLRT appears to have equal surgical morbidity and oncological outcome to TLRH in stage IB1 cervical cancer. Intraoperative complications did not differ significantly between these two groups. However, postoperative complications were fewer observed in TLRT. Because of the natural limitations of the retrospective study, the clinical value should be confirmed by multi-institutional prospective trial in the future.

Keywords: cervical cancer, laparoscopic radical trachelectomy, laparoscopic radical hysterectomy, preserve fertility

\section{Introduction}

The standard surgical procedure for patients with early-stage cervical cancer is radical hysterectomy and pelvic lymphadenectomy. The widespread use of cervical screening technique in our country has enabled the diagnosis of cervical cancer at its early stage. The current trend delaying childbearing and the second child policy in People's Republic of China have both caused a growing request for preserving 
fertility of patients. Radical trachelectomy, firstly reported by Dargent in 1994, is a viable option for patients with cervical cancer who wish to preserve their fertility. ${ }^{1}$ In recent years, with the rapidly growing availability of laparoscopy surgery, total laparoscopic radical trachelectomy (TLRT) procedure was widely accepted. To date, however, there have been limited data comparing the surgical and oncological safety of TLRT and total laparoscopic radical hysterectomy (TLRH). The aim of this study is to compare the surgical morbidity and oncological outcome of TLRT procedure with the TLRH procedure for stage IB1 (FIGO 2009) cervical cancer.

\section{Materials And Methods}

The research protocol was conducted in accordance with the guidelines on the World Medical Association's Declaration of Helsinki. All patients gave a written informed consent for their data to be collected and analyzed for scientific purpose. The institutional Review Board of Chaoyang Hospital affiliated to Capital Medical University approved the study.

\section{Eligibility Criteria And Patient Counseling} The inclusion criteria for TLRT group were as follows: 1) a strong desire to preserve fertility; 2) FIGO stage (2009) IB1 cervical cancer; 3) tumor diameter $\leqq 4 \mathrm{~cm}$; 4) no evidence of pelvic lymph node or distance metastases by imaging examination; and 5) underwent TLRT. Between January 2005 and December 2016, 46 patients were included in the TLRT group. During the same period, 73 patients who met the eligibility criteria of TLRT but underwent TLRH were represented in the control group. All the patients were operated on by the same group of surgeons at our institution. Prior to surgery, all patients and their spouses were comprehensively counseled on the benefits and potential risks of the treatment. All patients used graduated compression stockings and intermittent pneumatic compression during and after the operative procedures, and low-molecular weight heparin was used in high-risk patients.

The following data were collected: operative details (operative time, estimated blood loss EBL), intra- and postoperative complications classified according to Memorial Sloan Kettering Cancer Center surgical grading system.

\section{Total Laparoscopic Radical Trachelectomy}

In TLRT group, the lymph nodal status of the patients was assessed by two steps: 1) every patient was assessed by MRI examination; and 2) at the beginning of TLRT procedure, laparoscopic pelvic lymphadenectomy was performed. All dissected lymph nodes were sent for frozen section analysis. If the lymph nodes were positive, the patient would have been recommended to giving up preserving fertility and has been excluded from our study.

In TLRT group, tumor size was assessed by the MRI examination which is the best method of radiologic assessment of primary tumors greater than $10 \mathrm{~mm} .^{2,3}$ The patients with tumor size larger than $2 \mathrm{~cm}$ were offered neoadjuvant chemotherapy (NACT) firstly. To increase the efficacy of chemotherapeutic drugs and to control the local tumor growth, the uterine intra-arterial infusion method has been adopted in our study. NACT consisted of three agents. The regimen consisted of: bleomycin $20 \mathrm{mg} / \mathrm{m}^{2}$, cisplatin $80 \mathrm{mg} / \mathrm{m}^{2}$, and mitomycin $10 \mathrm{mg} / \mathrm{m}^{2}$. Two or three courses of this chemotherapy regimen were given at a 3 weeks interval. ${ }^{4}$ Clinical response was determined by pelvic examination and colposcopy 3 weeks after the last course of NACT. Responses to chemotherapy were recorded according to the WHO criteria. The patients that showed complete or partial response to NACT were planned for TLRT, while patients experiencing no change or disease progression would have been recommended to giving up preserving fertility and has been excluded from our study. Since 2012, the patients with tumor less than $2 \mathrm{~cm}$ recruited in TLRT group were accepted less radical trachelectomy. Less radical trachelectomy means that the uterosacral and cardinal ligaments were occluded and severed 1 to $2 \mathrm{~cm}$ from the cervix. The TLRT procedure was performed as described in our previous published study. ${ }^{5}$

\section{Total Laparoscopic Radical Hysterectomy}

The procedure was totally performed by laparoscopy. No uterus manipulator devices were used in our study, but the cervix was grasped with a cervical clamp and a self-made balloon-like solid occluder was emplaced in vagina in order to improve exposure and preserve an adequate pneumoperitoneum during colpotomy. The uterine vessels were coagulated and transected by titanium clips and the ultrasonic shears at their origin. The ureters were separated from their median attachments to the peritoneum and then unroofed to the point of their insertion into the bladder by right-angle separate nips, Hem-o-loks (544250, Teleflex Medical) and metallic hemaclips (LIGACLIP, Ethicon Endo-Surgery) without any energy equipment. This is our new invented operation skill called "parametrial thermal free technique (pTFT)". To reduce the risk of port-site metastasis, a tube was put in the vaginal canal, 
and removed the specimen from the tube to avoid contact with the vaginal wall, and the vaginal were thoroughly irrigated before continuous suturing.

\section{Postoperative Adjuvant Treatment}

In our study, postoperative adjuvant therapy was given to patients who had high-risk factor (deep cervical stromal invasion, lymphovascular space invasioin (LVSI), lymph node metastases, parametrial involvement, and positive surgical margin). Radiation treatment was recommended to patients who had at least one high-risk factor, and concurrent chemoradiation was given to the patients who had at least two high-risk factors. If the patient cannot accept the radiation treatment, chemotherapy was recommended. Patients with one high-risk factor were treated with 3-4 cycles of platinum-based adjuvant chemotherapy. Patients with at least two high-risk factors were treated with 4-6 cycles of platinum-based adjuvant chemotherapy. The regimen consisted of: TP, paclitaxel $135 \mathrm{mg} / \mathrm{m}^{2}$, and cisplatin $50 \mathrm{mg} / \mathrm{m}^{2}$ or TC, paclitaxel $135 \mathrm{mg} / \mathrm{m}^{2}$, and carboplatin $(\mathrm{AUC}=5)$ every 3 weeks.

\section{Statistical Analysis}

Data were analyzed using SPSS statistic software version 22.0 (SPSS version 22.0; SPSS, Inc., Chicago, IL). Continuous variables were compared by Student's $t$-test. The associations between the categorical data were assessed using the $X^{2}$ test. Fisher's exact test was used when necessary. Disease-free survival (DFS) time was calculated as the number of months from the date of surgery to the date of recurrence or the date of the last follow-up. Overall survival (OS) was calculated from the date of diagnosis to the date of death or the date of the last follow-up. DFS and OS were estimated using KaplanMeier curves. A log rank test was used to determine statistical significance. $\mathrm{P}$ values less than 0.05 were considered statistically significant.

\section{Results}

Forty-six patients underwent TLRT and 73 patients underwent TLRH between January 2005 and December 2016. The median age was 30 (19-40) years for TLRT group compared to 43 (31-65) years for TLRH group. There were significant differences in the median age between these two groups. No significant differences were found for the tumor size, histology, and pathology grade between TLRT group and TLRH group. Table 1 demonstrates the detailed pathology outcome of the two groups. Table 2 shows NACT group. There are 13 patients in TLRT group underwent NACT. No record of severe hematologic toxicity, sensory neuropathy, or renal failure after NACT has been found. All of the patients underwent surgery with a response to more than $50 \%$ of tumor size reduction. Two patients accepted postoperative adjuvant chemotherapy because the pathological report showed LVSI and parametrial invasion. Table 3 shows the surgical details and intraoperative and postoperative complications. In the TLRT group, the median operative time was 200 mins (range, 150-360mins) and the median blood loss was $200 \mathrm{~mL}$ (range, 50-400mL). In the TLRH group, the median operative time was 240 mins (range, 180-380) and the median blood loss was $250 \mathrm{~mL}$ (range, $10-1500 \mathrm{~mL}$ ). There was no significant difference between the two groups in terms of the intraoperative complications. However, the number of patients that had postoperative complications was higher in the TLRH group. Some patients had more than one postoperative complication. Table 4 shows the type of postoperative complications according to organ system and grade. Urinary system complications were the relative common postoperative complications. Table 5 demonstrates the survival outcomes of the patients. The median follow-up time was 80 months for TLRT group and 72 months for TLRH group. No patient in TLRT group developed recurrence. However, there were 2 recurrences diagnosed in the TLRH group. One patient had stage IB1 (tumor size $=2.5 \times 2.5 \mathrm{~cm}$ ) squamous carcinoma. During her sixth cycle postoperative chemotherapy, the patient had right side inguinal lymph nodes metastasis confirmed with pathology examination. Then, she received radiation. She is still alive at our last follow-up. Another patient had IB1 (tumor size $=2 \times 2 \mathrm{~cm}$ ) intermediate grade adenosquamous carcinoma. She received 4 cycles chemotherapy and 25 times radiation. One year after operation, she found CEA and CA125 increased, but no pathology examination. Fifty months after operation, the patient was diagnosed with acute monocytic leukemia and 24 months after operation, the patient died due to acute monocytic leukemia.

\section{Discussion}

Radical hysterectomy has been the recommended standard surgery for early-stage cervical cancer, but it brought patients loss of fertility. Since Dargent introduced LVRT in 1987 and first reported its use in 1994, more than 1000 cases of LVRT have been reported. The tumor recurrence rate is between $4.2 \%$ and $5.3 \%$, and the mortality rate is between $2.5 \%$ and $3.2 \%{ }^{6}$ However, LVRT has several 
Table I Demographic And Pathology Outcomes Of TLRT And TLRH Groups

\begin{tabular}{|c|c|c|c|}
\hline & $\operatorname{TLRT}(n=46)$ & TLRH $(n=73)$ & P-value \\
\hline Age (years), median (range) & $30,(19-40)$ & $43,(31-65)$ & 0.03 \\
\hline FIGO stage IBI (2009) & & & NS \\
\hline Tumor size $<2 \mathrm{~cm}$ & 33 (7I.7\%) & $48(65.8 \%)$ & \\
\hline Tumor size $\geq 2 \mathrm{~cm}$ & $13(28.2 \%)$ & $25(34.2 \%)$ & \\
\hline Histology & & & NS \\
\hline Squamous carcinoma & 43 (93.5\%) & $63(86.3 \%)$ & \\
\hline Adenocarcinoma & $3(6.5 \%)$ & $6(8.2 \%)$ & \\
\hline Others & 0 & $4(5.5 \%)$ & \\
\hline Pathology grade & & & NS \\
\hline Not reported & 0 & $4(5.5 \%)$ & \\
\hline Low grade & $20(43.5 \%)$ & $31(42.5 \%)$ & \\
\hline Intermediate grade & 14 (30.4\%) & $21(28.8 \%)$ & \\
\hline High grade & $12(26.1 \%)$ & 17 (23.2\%) & \\
\hline Lymph vascular space invasion & $2(4.3 \%)$ & $19(26 \%)$ & 0.001 \\
\hline Depth of invasion (mm), median (range) & $5.5(1-15)$ & $5.7(I-15)$ & NS \\
\hline No. of dissected lymph nodes, median(range) & $25(14-37)$ & $23(10-35)$ & NS \\
\hline No. of patients with lymphatic metastasis & 0 & $9(12.3 \%)$ & 0.00 \\
\hline Positive margin, $\mathrm{N}$ & 0 & 0 & NS \\
\hline Paramatrial invasion & $\mathrm{I}(2.2 \%)$ & $6(8.2 \%)$ & 0.02 \\
\hline No. of patients receiving postoperative adjuvant therapy & $2(4.3 \%)$ & $22(30.1 \%)$ & 0.006 \\
\hline No. of patients receiving radiation & 0 & 9 & \\
\hline No. of patients receiving chemotherapy & 2 & 8 & \\
\hline No. of patients receiving concurrent chemoradiation & 0 & 5 & \\
\hline
\end{tabular}

limitations despite results demonstrating the safety of the procedure. One limitation is that it is a challenging procedure for nulliparous patients and those with a history of previous conization with adverse vaginal anatomy. In addition, it has a longer study curve to master vaginal procedure. The most important is that LVRT has been advised not to be performed in patients with tumors larger than $2 \mathrm{~cm}$ because of a high relapse rate. ${ }^{7,8}$ Abdominal radical trachelectomy follows steps identical to those of abdominal radical hysterectomy. However, abdominal radical trachelectomy has the disadvantages of significant blood loss, the need for a large abdominal incision, a requirement for a longer postoperative hospital stay, and postoperative adhesion. With the progress in laparoscopic skills and instrumentation, TLRT seemed to solve these problems.

In our study, there was no significant difference between the two groups in terms of the intraoperative complications. The rate of patients who had postoperative complications was lower in the TLRT group. Complications of radical treatment including damage to the bladder, bowel and ureter, nerve injury leading to bladder and bowel dysfunction, fistula formation that have a significant impact on the patients' quality of life., 90 Urologic complications are due to the wide parametrial resection. Less radical procedure can decrease the urologic complications. As we all known that whether parametrial involvement is associated with tumor diameter. For patients with no lymph node metastases, no LVSI, and tumor diameter smaller than $2 \mathrm{~cm}$, parametrial disease was identified in only $0.4 \% .^{11,12}$ Therefore, in TLRT group, patients with tumor size less than $2 \mathrm{~cm}$ were performed less radical trachelectomy (from 2012 year). In our study, no urologic injury has been reported. Incidence rates of urologic infection and dysfunction are $6.5 \%$ in TLRT 
Table 2 Demographic And Pathology Outcomes Of Patients Underwent Neoadjuvant Chemotherapy

\begin{tabular}{|c|c|c|c|c|c|c|c|c|c|c|}
\hline No. & $\begin{array}{l}\text { Age } \\
\text { (years) }\end{array}$ & $\begin{array}{l}\text { Tumor } \\
\text { Size } \\
\text { (cm) }\end{array}$ & Histology & $\begin{array}{l}\text { Pathology } \\
\text { Grade }\end{array}$ & $\begin{array}{l}\text { Surgical } \\
\text { Procedure }\end{array}$ & $\begin{array}{l}\text { Lymph } \\
\text { Vascular } \\
\text { Space } \\
\text { Invasion }\end{array}$ & $\begin{array}{l}\text { Depth } \\
\text { Of } \\
\text { Invasion } \\
(\mathbf{m m})\end{array}$ & $\begin{array}{l}\text { Positive } \\
\text { Margin }\end{array}$ & $\begin{array}{l}\text { Paramatrial } \\
\text { Invasion }\end{array}$ & $\begin{array}{l}\text { Postoperative } \\
\text { Adjuvant } \\
\text { Therapy }\end{array}$ \\
\hline Case I & 25 & 2.5 & Squamous carcinoma & $\begin{array}{l}\text { Intermediate } \\
\text { grade }\end{array}$ & TLRT & No & 3 & No & No & No \\
\hline Case 2 & 24 & 3.0 & Squamous carcinoma & Low grade & TLRT & No & 5 & No & No & No \\
\hline Case 3 & 27 & 2.5 & Squamous carcinoma & Low grade & TLRT & No & 5 & No & No & No \\
\hline Case 4 & 22 & 3.3 & Squamous carcinoma & Low grade & TLRT & No & 3 & No & No & No \\
\hline Case 5 & 30 & 4.0 & Squamous carcinoma & $\begin{array}{l}\text { Intermediate } \\
\text { grade }\end{array}$ & TLRT & Yes & 6 & No & No & $\begin{array}{l}\text { Chemotherapy } 4 \\
\text { cycles }\end{array}$ \\
\hline Case 6 & 33 & 3.5 & Squamous carcinoma & Low grade & TLRT & No & 4 & No & No & No \\
\hline Case 7 & 33 & 2.0 & Squamous carcinoma & High grade & TLRT & No & 15 & No & No & No \\
\hline Case 8 & 35 & 4.0 & Adenocarcinoma & Low grade & TLRT & Yes & 11 & No & Yes & $\begin{array}{l}\text { Chemotherapy } 6 \\
\text { cycles }\end{array}$ \\
\hline Case 9 & 26 & 2.5 & Squamous carcinoma & High grade & TLRT & No & 9 & No & No & No \\
\hline Case 10 & 30 & 3.5 & Squamous carcinoma & Low grade & TLRT & No & 3 & No & No & No \\
\hline Case II & 28 & 3.0 & Squamous carcinoma & $\begin{array}{l}\text { Intermediate } \\
\text { grade }\end{array}$ & TLRT & No & 12 & No & No & No \\
\hline Case 12 & 27 & 3.7 & Squamous carcinoma & High grade & TLRT & No & 8 & No & No & No \\
\hline Case 13 & 37 & 2.8 & Squamous carcinoma & $\begin{array}{l}\text { Intermediate } \\
\text { grade }\end{array}$ & TLRT & No & 7 & No & No & No \\
\hline
\end{tabular}

Table 3 Surgical Details And Intra/postoperative Complications Of TLRT And TLRH Groups

\begin{tabular}{|c|c|c|c|}
\hline & TLRT & TLRH & P-value \\
\hline $\begin{array}{l}\text { Operative time } \\
(\mathrm{min}) \text {, median (range) }\end{array}$ & $200,(150-360)$ & $240,(180-380)$ & NS \\
\hline $\begin{array}{l}\text { Estimated blood loss } \\
(\mathrm{mL}), \text { median (range) }\end{array}$ & $200,(50-400)$ & $250,(10-1500)$ & NS \\
\hline $\begin{array}{l}\text { Intraoperative } \\
\text { complications, n (\%) }\end{array}$ & 0 & I & NS \\
\hline Bladder damage & 0 & 0 & \\
\hline Ureter damage & 0 & 0 & \\
\hline Bowel damage & 0 & 0 & \\
\hline Vessels injury & 0 & I & \\
\hline Nerve injury & 0 & 0 & \\
\hline $\begin{array}{l}\text { Postoperative } \\
\text { complications, n (\%) }\end{array}$ & 6 & 38 & 0.02 \\
\hline
\end{tabular}

group. Vieira et al demonstrated that incidence rates of urologic infection and dysfunction after LRT and robotic radical trachelectomy procedures were $11.9 \%$, and after abdominal radical trachelectomy were $17.2 \% .{ }^{13}$ Guo et al showed that the urologic dysfunction rate after abdominal radical trachelectomy was $9.8 \% .{ }^{14}$ Several studies have reported that a tumor size larger than $2 \mathrm{~cm}$ is a high-risk factor of recurrence because of insufficient parametrial excision. ${ }^{15}$ How to treat the patients with tumor size lager than $2 \mathrm{~cm}$ ? In our series, we offered NACT via the uterine arteries to the patients with tumor diameter more than $2 \mathrm{~cm}$. The advantage of NACT includes significant reduction of the size of the cervical tumor and an increase in operability of the lesion. Reduction of tumor volume makes surgery easier, especially parametrial resection, and therefore, a reduction in the number of complications would be expected. For patients with locally advanced cervical tumor, intra-arterial chemotherapy may increase tumor exposure to high drug concentrations while decreasing drug delivery to systemic tissues. ${ }^{16-18}$

Our low complications also contributed to a new invented operation skill called "pTFT". The ureters were separated from their median attachments to the peritoneum and then unroofed to the point of their insertion into the bladder by right-angle separate nips, Hem-o-loks (544250, 
Table 4 Type Of Postoperative Complications According To Organ System And Grade

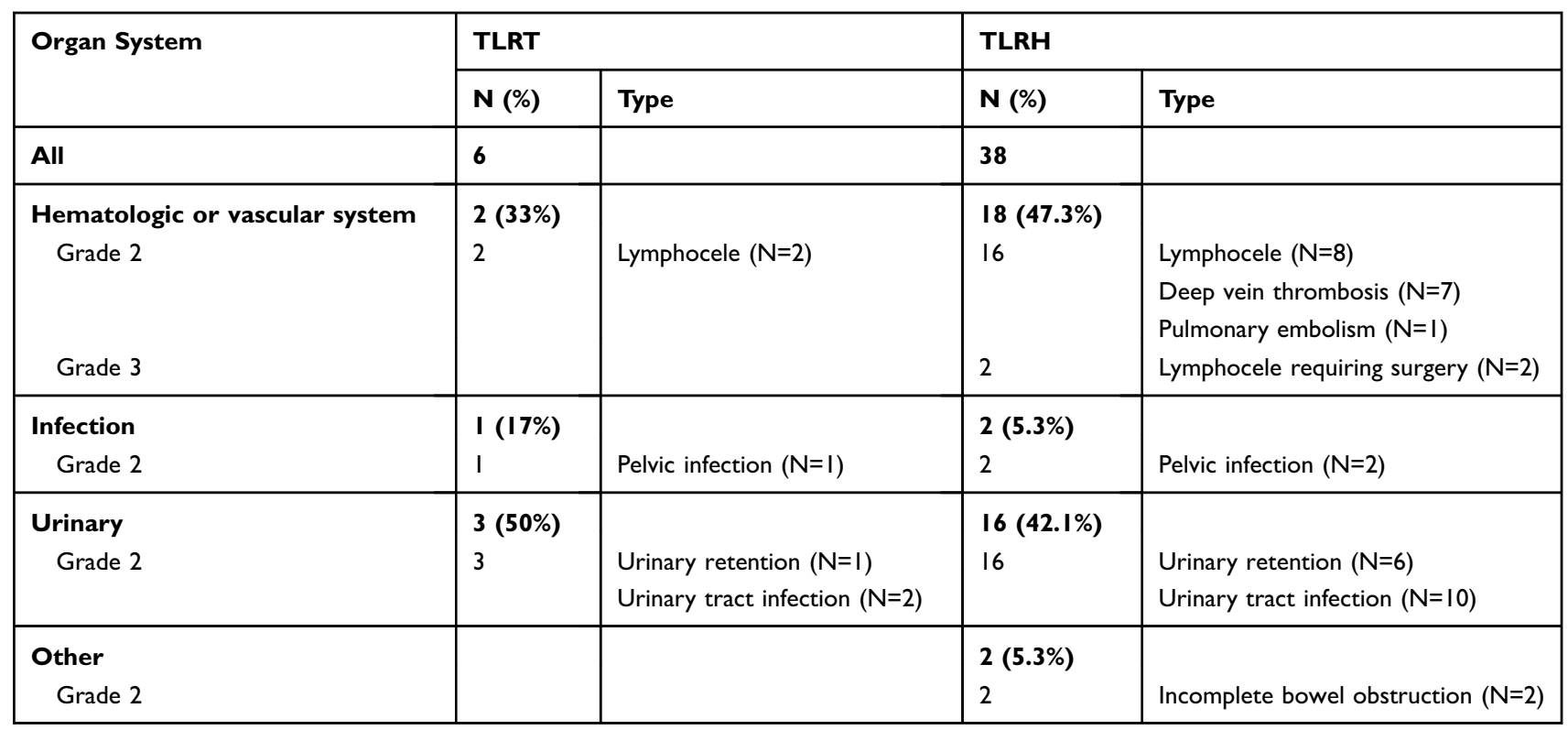

Notes: Bold represents the number and rate of complications of the single organ system and not of the grade's subgroups.

Table 5 Survival Outcomes Of TLRT And TLRH Groups

\begin{tabular}{|l|l|l|l|}
\hline & TLRT & TLRH & P-value \\
\hline $\begin{array}{l}\text { Follow up (month), } \\
\text { median (range) }\end{array}$ & $80,(28-149)$ & $72,(26-153)$ & NS \\
Recurrence, no (\%) & 0 & $2,(2.73 \%)$ & NS \\
Death, no (\%) & 0 & $1,(1.37 \%)$ & NS \\
Overall survival rate, \% & $100 \%$ & $98.63 \%$ & NS \\
\hline
\end{tabular}

Teleflex Medical) and metallic hemaclips (LIGACLIP, Ethicon Endo-Surgery) without using any energy equipment. This is our skill to prevent the urologic complications, and we call it "pTFT".

In our series, the DFS and OS rates in the TLRT group were equal to the TLRH group. The satisfied DFS and OS rates of TLRT in stage IB1 cervical cancer may due to the following reasons. First, we treated the patients with different methods depending on the tumor diameter. When tumor size is less than $2 \mathrm{~cm}$, we choose less radical trachelectomy. However, when the tumor size is larger than $2 \mathrm{~cm}$, the incidence of parametrial involvement is significantly higher. Therefore, we offered NACT followed by a radical resection of parametrial tissue. Second, NACT is a way that guarantees the satisfactory outcome. Previous studies show that NACT can shrink the tumor size, inhibit tumor micrometastases, and enhance the rate of success resection. ${ }^{19,20}$ A meta-analysis showed that NACT followed by radical hysterectomy can improve the survival rate. ${ }^{21} \mathrm{He}$ et al have reported that NACT via AI had significantly higher effective rate, and significantly lower adverse effect than NACT via IV. 2-3 cycles NACT had the optimal efficacy of up to $90 \%$, which was higher than that of one cycle chemotherapy about $70 \%{ }^{22}$ Last but not least, all of the procedures including TLRT and TLRH were performed by the same surgeon who has rich experiences.

To the best of our knowledge, this study is the first series comparing the surgical and oncological outcome of TLRT versus TLRH from a single institution by the same surgeon. Admittedly, potential limitations of this study are represented by the retrospective design. Although RCT is the highest evidence level, randomized study is not feasible because ethical issue involved in selecting patient who wish to preserve fertility. Because the study was retrospective, there was not a uniform standard for intraoperative and postoperative management (eg, NACT and postoperative adjuvant therapy). It was a retrospective study limited to our own institution, and our findings may not be applicable to others.

\section{Conclusion}

TLRT appears to have equal surgical morbidity and oncological outcome to TLRH in stage IB1 cervical cancer. Expanding the inclusion criteria of TLRT to tumors $>2 \mathrm{~cm}$ could significantly increase the need for NACT. Intraoperative complications did not differ significantly between these two groups. However, postoperative complications were fewer observed in TLRT procedure. Because of the natural limitations of the 
retrospective study, the clinical value should be confirmed by multi-institutional prospective trial in the future.

\section{Acknowledgments}

The present study was supported by the Beijing Municipal Administration of Hospitals Clinical Medicine Development of special funding Yangfan Project (no. ZYLX201713).

\section{Disclosure}

The authors declare that they have no conflicts of interest in this work.

\section{References}

1. Dargent D, Brun L, Roy M. La trachélectomie élargie (T.E.). Une alternative à l'hystérectomie radicale dans le traitement des cancers infiltrants développés sur la face externe du col utérin. $J$ Obstet Gynecol. 1994;2:292-295.

2. Hricak H, Gatsonis C, Chi DS, et al. Role of imaging in pretreatment evaluaton of early invasive cervical cancer: results of the intergroup study American College of Radiology Imaging Network 6651Gynecologic Oncology Group 183. J Clin Oncol. 2005;23:93299337. doi:10.1200/JCO.2005.02.0354

3. Bipat S, Glas AS, van der Velden J, Zwinderman AH, Bossuyt PM, Stoker J. Computed tomography and magnetc resonance imaging in staging of uterine cervical carcinoma: A systematc review. Gynecol Oncol. 2003;91:59-66. doi:10.1016/S0090-8258(03)00409-8

4. Qi L, Yunhe Z, Shuzhen W, et al. Neoadjuvant intra-arterial chemotherapy followed by total laparosocpic radical trachelectomy in stage IB1 cervical cancer. Fertil Steril. 2014;101:812-817. doi:10.1016/j.fertnstert.2013.12.001

5. Qi L, Yunhe Z, Chongdong L, Shuzhen W, Shuli G, Zhenyu Z. Total laparoscopic radical trachelectomy in the treatment of early squamous cell cervical cancer: A retrospective study with 8-year follow-up. Gynecol Oncol. 2013;130:275-279. doi:10.1016/j.ygyno.2013.04.470

6. Martinez A, Poilblanc M, Ferron G, De C, Jouve E, Querleu D. Fertilitypreserving, surgical procedures, techniques. Best Pract Res Clin Obstet Gynaecol. 2012;26:407-424. doi:10.1016/j.bpobgyn.2012.01.009

7. Plante M, Gregoire J, Renaud MC, Roy M. The vaginal radical trachelectomy: an update of a series of 125 cases and 106 pregnancies. Gynecol Oncol. 2011;121:290-297. doi:10.1016/j.ygyno.2010. 12.345

8. Cao DY, Yang JX, Wu XH, et al. Comparisons of vaginal and abdominal radical trachelectomy for early-stage cervical cancer: preliminary results of a multi-center research in China. Brit $J$ Cancer. 2013;109:2778-2782. doi:10.1038/bjc.2013.656

9. Covens A, Rosen B, Murphy J, et al. Changes in the demographics and perioperative care of stage $\mathrm{IA}(2) / \mathrm{IB}(1)$ cervical cancer over the past 16 years. Gynecol Oncol. 2001;81:133-137. doi:10.1006/gyno.2001.6158
10. Reade CJ, Eiriksson LR, Covens A. Surgery for early stage cervical cancer: how radical should it be? Gynecol Oncol. 2013;131:222-230. doi:10.1016/j.ygyno.2013.07.078

11. Wright JD, Grigsby PW, Brooks R, et al. Utility of parametrectomy for early stage cervical cancer treated with radical hysterectomy. Cancer. 2007;110:1281-1286. doi:10.1002/cncr.22899

12. Frumovitz M, Sun CC, Schmeler KM, et al. Parametrial involvement in radical hysterectomy specimens for women with early-stage cervical cancer. Obstet Gynecol. 2009;114:93-99. doi:10.1097/ AOG.0b013e3181ab474d

13. Marcelo AV, Gabriel JR, Mark M, et al. Radical trachelectomy in early-stage cervical cancer: A comparison of laparotomy and minimally invasive surgery. Gynecol Oncol. 2015;138:1-5. doi:10.1016/j. ygyno.2015.06.004

14. Jing G, Ying Z, Xiaofei C, Lin S, Kai C, Xiugui S. Surgical and oncologic outcomes of radical abdominal trachelectomy versus hysterectomy for stage IA2-IB1 cervical cancer. J Minim Invasive Gynecol. 2018;26:484-491.

15. Nishio H, Fujii T, Kameyama K, et al. Abdominal radical trachelectomy as a fertility-sparing procedure in women with early-stage cervical cancer in a series of 61 women. Gynecol Oncol. 2009;115:5155. doi:10.1016/j.ygyno.2009.06.036

16. Scarabelli C, Zarreli A, Gallo A, Visentin MC. Multimodal treatment with neoadjuvant intraarterial chemotherapy and radical surgery in patients with stage IIIB-IVA cervical cancer. A preliminary study. Cancer. 1995;76:1019-1026. doi:10.1002/1097-0142(19950915) 76:6<1019::aid-cncr2820760616>3.0.co;2-4

17. Park SY, Kim BG, Kim JH, Lee JH. Phase I/II study of neoadjuvant intraarterial chemotherapy with mitomycin-C, vincristine, and ciaplatin in patients with stage IIb bulky cervical carcinoma. Cancer. 1995;76:814-823. doi:10.1002/1097-0142(19950901)76:5<814::aidcncr2820760516>3.0.co;2-r

18. Kigawa J, Minagawa Y, Ishihara H, Itamochi KY, Terakawa N. The role of neoadjuvant intraarterial infusion chemotherapy with cisplatin and bleomycin for locally advanced cervical cancer. Am J Clin Oncol (CCT). 1996;19:255-259. doi:10.1097/00000421-199606000-00009

19. Hwang YY, Moon H, Cho SH, et al. Ten-year survival of patients with locally advanced, stage Ib-IIb cervical cancer after neoadjuvant chemotherapy and radical hysterectomy. Gynecol Oncol. 2001;82:8893. doi:10.1006/gyno.2001.6204

20. Cho YH, Kim DY, Kim JH, et al. Comparative study of neoadjuvant chemotherapy before radical hysterectomy and radical surgery alone in stage IB2-IIA bulky cervical cancer. $J$ Gynecol Oncol. 2009;20:22-27. doi:10.3802/jgo.2009.20.1.22

21. Robova H, Rob L, Halaska MJ, Kim YM, Kim YT, Nam JH. Review of neoadjuvant chemotherapy and trachelectomy: which cervical cancer patients would be suitable for neoadjuvant chemotherapy followed by fertility-sparing surgery? Curr Oncol Rep. 2015;17:446. doi:10.1007/s11912-015-0446-0

22. Yun H, Qun ZH, Yu G, et al. Analysis of short-term efficacy as defined by RECIST and pathological response of neoadjuvant chemotherapy comprised paclitaxel and cisplatin followed by radical surgery in patients with locally advanced cervical cancer A prospective observational study. Medicine. 2018;97:e10913. doi:10.1097/ MD.0000000000010913
OncoTargets and Therapy

\section{Publish your work in this journal}

OncoTargets and Therapy is an international, peer-reviewed, open access journal focusing on the pathological basis of all cancers, potential targets for therapy and treatment protocols employed to improve the management of cancer patients. The journal also focuses on the impact of management programs and new therapeutic agents and protocols on patient perspectives such as quality of life, adherence and satisfaction. The manuscript management system is completely online and includes a very quick and fair peer-review system, which is all easy to use. Visit http://www.dovepress.com/ testimonials.php to read real quotes from published authors. 